\title{
International Authorship of Articles Published in JTPE 2009-2018
}

The purpose of the Journal of Teaching in Physical Education (JTPE) is to "communicate national and international research and stimulate discussion, study, and critique of teaching, teacher education, and curriculum as these fields relate to physical activity in schools, communities, higher education, and sport." This purpose statement is presented within JTPE's mission statement, which can be found on the JTPE website (https://journals.humankinetics.com/view/journals/jtpe/jtpeoverview.xml). It is important that from time to time one examines the mission of an organization to ascertain whether or not it is actually meeting the proposed mission. In this Editor's Note, we specifically investigate the meaning of the word "international" within the purpose statement. In doing so, we present data here about the contributions (publications) from those who belong to our "international" research community in physical education. The definition of "international" used in this Editor's Note is as follows - authors whose professional affiliation is reflected in a country outside of the United States.

To determine the number of "international" articles published in JTPE 2009-2018, the name of the university, school, and/or organization listed for each contributing author of each article was examined. Each article published that reflected at least a 50\% level of "international" authorship was identified as an "international" publication. This criterion was used to best reflect the purpose of the task at hand, which was to identify the number of articles published in JTPE over the past decade by members of the international research community in the field of physical education.

Over the past decade, a total of 314 articles were published in $J T P E$ including those associated with monographs and special issues. Between 2009 and 2018, the number of articles published in JTPE by individuals from the "international" community ranged between $15 \%$ and 55\% each year. The yearly average of "international" publications over this 10 -year period was $40 \%$. In 8 of the 12 years, the percentage of "international" publications was equal to or greater than one-third of the whole. Since 2013, the number of "international" publications has not dropped below 33\%; in fact, only in 2014 and 2017 did the number dip below $40 \%$. The number of articles published each year in JTPE and those identified as "international" during this time period are presented in Table 1.

The "international" authorships associated with articles published in JTPE 2009-2018 were also examined for country of origin of the articles' authors. A total of 31 different countries were represented across the 125 "international" articles published. The largest number of "international" publications originated from authors residing in Australia and England, with more than 20 publications from each country. This was followed by authors living in Belgium, Canada, China, Ireland, New Zealand, and Spain, each having 10-15 publications, and authors living in France, Finland, Greece, Hong Kong, Israel, Netherlands, South Korea, and Turkey, each having 4-7 publications. From 1-3 publications originated from authors living in each of the remaining 15 countries (see Table 2).

So, what do these data tell us about publications in JTPE? First, JTPE has published a significant number of articles from members of the "international" research community in the field of physical education over the past decade. A $40 \%$ contribution seems to be quite substantive in a journal based in the United States. It suggests that JTPE is a viable outlet for "international" publications. Second, the "international" publications reflect considerable diversity across the world's nations. Six of the seven continents of the world (Africa, Asia, Australia,

Table 1 Number of Articles Published Reflecting International Authorship of $\mathbf{5 0 \%}$ or More Published 2009-2018

\begin{tabular}{lccc}
\hline Year & $\begin{array}{c}\text { Number of articles } \\
\text { published per year }\end{array}$ & $\begin{array}{c}\text { Number of } \\
\text { international articles }\end{array}$ & $\begin{array}{c}\text { Percentage of } \\
\text { international articles (\%) }\end{array}$ \\
\hline 2009 & 23 & 11 & 48 \\
2010 & 24 & 7 & 29 \\
2011 & 26 & 4 & 15 \\
2012 & 23 & 6 & 26 \\
2013 & 26 & 13 & 50 \\
2014 & 30 & 10 & 33 \\
2015 & 39 & 21 & 54 \\
2016 & 37 & 15 & 41 \\
2017 & 44 & 15 & 34 \\
2018 & 42 & 23 & 55 \\
Total & 314 & 125 & 40 \\
\hline
\end{tabular}


Table 2 Authorship Country Affiliation of International Articles Published 2009-2018

\begin{tabular}{ll}
\hline Number of articles & Country affiliations of authors \\
\hline$>20$ & Australia and England \\
$13-19$ & Belgium, Canada, China, and Spain \\
$8-12$ & Ireland and New Zealand \\
$4-7$ & France, Finland, Greece, Hong Kong, Israel, Netherlands, South Korea, and Turkey \\
$1-3$ & Brazil, Chile, Cyprus, Estonia, Germany, Japan, Norway, Poland, Portugal, Scotland, Singapore, South Africa, \\
& Sweden, Switzerland, and Taiwan \\
\hline
\end{tabular}

Europe, North America, and South America) are represented in the authorships of these "international" publications. Another note of interest worth mentioning here that supports the "international" element of JTPE's purpose statement is, of 345 manuscripts submitted to JTPE in $2018,65 \%$ originated from "internationals." In summary, yes, we welcome authors from around the world to submit their research studies to JTPE.

Mark Byra and Bryan McCullick, Co-editors Journal of Teaching in Physical Education 